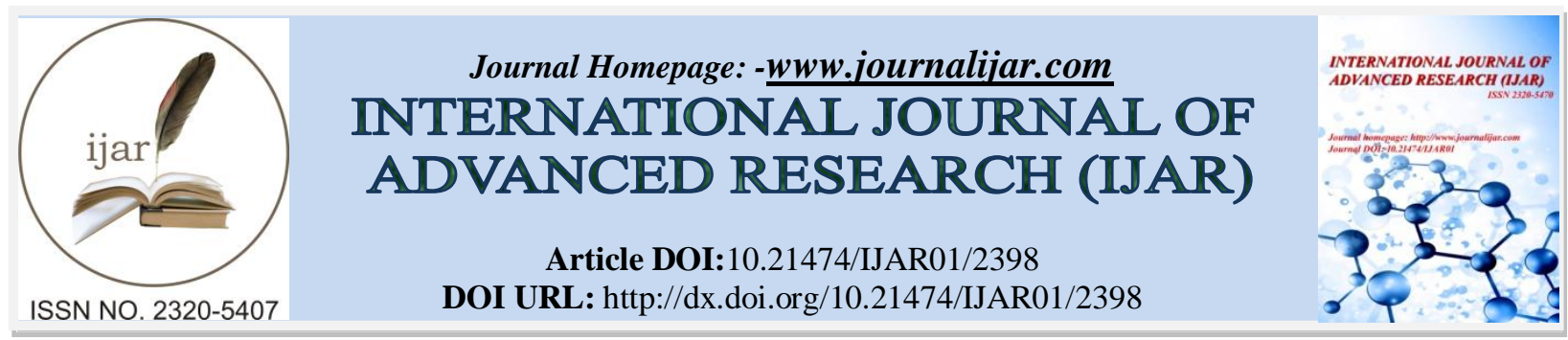

RESEARCH ARTICLE

\title{
PREVALENCE AND EVALUATION OF HAIR LOSS AND IRRITABLE BOWEL SYNDROME AMONG MEDICAL STUDENTS AND ITS EFFECT ON THEIR LIFESTYLE ANDEDUCATIONAL ATTAINMENT, IN TAIBAHUNIVERSITY, AL-MADINAH AL-MUNAWARAH.
}

\author{
Mohammed Adel Makkawi, Hatem Mohammed Ahmed, Abdullah Mohammed Alattas, Arwa Talal Malosh \\ Lujain Khaled Alharbi and Khalid Ahmed Amara.
}

\section{Manuscript Info \\ Manuscript History \\ Received: 19 October 2016 \\ Final Accepted: 20 November 2016 \\ Published: December 2016}

Key words:-

\section{Abstract}

Objective: - This study aimed to assess the prevalence of Hair loss \& Irritable Bowel Syndrome among medical school students, and to evaluate its effect on their lifestyle and study, in Taibah University, Madinah.

Subjects and Methods: - a cross-sectional survey was conducted through a random sampling, across medical students mainly from Madinah. The final study sample size was 250 students. The questionnaires were distributed both manually and electronically, the questionnaire includes 41 questions, discussing various aspects in the student's social, medical and psychological life. Statistical analysis system used to analyze the collected data.

Results: - The majority of the studied subjects showed no statistically significant differences between male and female subjects in almost all aspects of the study. (46.1\%) of subjects have hair loss (alopecia), $(37.2 \%)$ have irritable bowel syndrome. both diseases were presented with extreme statistical significance ( $\mathrm{p}$ value $<0.0001$ ). almost all the subjects feel stressed, (94\%) thought that studying in the college of medicine and having too much work are the main causes of this stress. Conclusions: -A higher prevalence of irritable bowel syndrome among medical students and interns in Madina, Saudi Arabia, and it affects the educational attainment and the academic performance for half of these students. Hair loss affects or interferes with student's life in general. But affects the academic performance (stress) for few of students.

Objectives: -

General objective:

To Assess the prevalence of Hair loss \& IBS among medical school students, and to evaluate its effect on their lifestyle and study.

\section{Specific objectives:}

1. Assess the prevalence of IBS among medical student

2. Assess the prevalence of hair loss among medical student

3. Assess the awareness of medical student about stress related complications. 
4. To evaluate the degree of hair loss \& IBS in socially active students $\&$ students with high grades compared to others.

5. To differentiate between hair loss \&IBS due to medical school stress and other risk factors.

6. To assess medical seeking of their conditions.

7. To assess the impact of hair loss \& IBS on students' lifestyle, selfimage and educational attainment.

Copy Right, IJAR, 2016, All rights reserved.

\section{Introduction: -}

Stress is the "wear and tear" our bodies experience as we adjust to our continually changing environment; it has physical and emotional effects and can create positive or negative influence on us. As a positive influence, stress can help to compel us for action. As a negative influence, it can result in feelings of distress, rejection, anger, and depression, which in turn can lead to health problems [1]. Studies revealed that medical students experience a relatively high level of personal distress, with adverse consequences on academic performance, competency, professionalism, and may cause health problems such as Irritable bowel syndrome and hair loss. Stress in medical students has been a global issue [2].

Irritable bowel syndrome (IBS) is a functional GI disorder presented as abdominal pain and altered bowel habits with no specific organic pathology. Microscopic inflammation although has been documented in some patients [3]. IBS in the past has been considered a diagnosis of exclusion. However, although it does have a broad differential diagnosis, now is not considered a diagnosis of exclusion [4]. The cause of IBS is not clearly defined, but there is a lot of research to find it out. Around $11 \%$ of population globally is affected. And just around $30 \%$ of people who experience the symptoms consult physicians for their IBS symptoms. The people who seek for consultation does not have different abdominal symptoms to those who do not consult, but they have low quality of life and greater levels of anxiety [5].

On the other hand, hair is the second fastest growing tissue of human body. Normal hair fall is 50-100 hair per day; if hair fall exceeds this limit, it is termed as 'balding' or alopecia. There are many reasons why men and women lose their hair, but according to a case-control study, stress may be the primary reason for unexplained hair loss [6]. A study done in KSU in Saudi Arabia showed that high prevalence of stress among medical students is a cause of concern as it may impair behavior of students, diminish learning, and ultimately affect patient care after their graduation. The overall prevalence of stress in the study was 63.7\% (Sample of 775) [7]. Another study carried out in College of Health Sciences in Ethiopia also showed a high prevalence of stress among medical students indeed needed attention the overall prevalence of stress in the study was 52.4\% (Sample of 329) [8]. A cross-sectional study carried out in Sweden showed that $1^{\text {st }}$ year students indicated experiencing the highest degree of pressure from studies. A gender difference regarding stress levels was also seen, where females reported higher levels of stress than males [9]. Another study done among students of a medical college in southern India of 278 students, among hair morbidities commonest was hair loss seen in 165 (59.3\%) cases [10].

And for IBS, A study had conducted in California university Shows that IBS is stress sensitive disorder, explained by bodily function and behavior can be affected by a neurobiological model which postulates stress induced alteration in arousal circuits and central stress and activation of parallel motor outputs from brain regions [11]. Other study done in Texas Southern University College of Pharmacy and Health Sciences, conduct on children and adolescents shows that IBS is distressing and have a negatively impacts on patients 'school and social life' and therapy option have good outcomes [12]. An observational case-control study in Dow University of Health Sciences, Karachi, Pakistan shows that medical student who suffer from anxiety and mental stress are more associated with IBS [13]. Another cross-sectional study carried out in China-Japan Friendship Hospital, on medical students shows that IBS affects 33.3\% (sample 683) of students, and student-life stress inventory is high in IBS patients [14]. Study carried out in King Abdulaziz University, Jeddah, Saudi Arabia on medical students and interns shows a high prevalence of IBS, and the predictors of IBS is emotional stress, female gender, morbid anxiety and high grade [15]. 
In our research, we are looking to estimate the prevalence of IBD and hair loss in medical students in Taibah university and the relation between them and stress due to medical school comparison to grade, gender, year of study, eating habits and family history. So, by greater recognizing of the cause of IBs and hair loss among medical student it may help to guide for more effective management of the symptoms.

\section{Methodology: - \\ Study design: -}

This is a cross-sectional study which was conducted through a random sampling. The population was medical students mainly from Al-Madinah Al-Munwarah region in Saudi Arabia during April and May 2016. The aim of this study is to assess the prevalence of hair loss and Irritable Bowel Syndrome (IBS) among the medical school students in Taibah University and to evaluate their effect on the student's lifestyle and educational attainment.

All recruited subjects of this study were actively involved in studying medical courses. Subjects who are not medical students or finished their medical courses for a period more than two years were excluded from the study analysis. A pre-designed structured English language questionnaire was used in this cross-sectional survey. The used questionnaire was formulated to include demographic aspects, clinical features, nutritional, medical and psychosocial history. The questionnaire includes 41 questions, discussing various aspects in the student's social, medical and psychological life. The questionnaire items were designed and written to suit the tradition and the Islamic culture of the Holly Al-Madinah Al-Munwarah City.

The questionnaires were distributed both manually and electronically on a large scale to get the effective sampling. The questionnaires with missing data more than $50 \%$ were excluded from the study analysis. The final study sample size was 250 medical students.

Approval was taken from the ethics committee at faculty of medicine, Taibah University. Ethical consideration was considered to avoid physical or emotional harm in the study questionnaire. The confidentiality and privacy of the collected data were ensured through the use of anonymous questionnaire and during data entry and analysis. People were provided with information on the study aims and methods.

\section{Statistical analysis: -}

The collected data were analyzed using statistical analysis system (SAS). Data from the questionnaire has been entered as numerical or categorical, as appropriate. Two types of statistics have been done:

1. Descriptive statistics; where quantitative data was shown as mean \pm S.D for the students in each group, and qualitative data was expressed as frequency and percent which plays the proportion of participants who are represented within each category.

2. Analytical statistics: where Chi- square test between qualitative variables. Also, unpaired Student's t-test was used as a test of significance for comparison between two arithmetic means of two different groups. The level of statistical significance was defined as $\mathrm{P} \leq 0.05$.

\section{Results: -}

A cohort of 247 medical students at Taibah university (126 males, 51\%) and 121 females, 49\%) respond to the questionnaire. The study assessed the prevalence of hair loss and Irritable Bowel Syndrome (IBS) and evaluated their effect on the student's lifestyle and educational attainment through a population-based cross-sectional study.

Table 1, presented the socio-demographic characteristics of the studied cohort. Nearly equal proportion of male $(51 \%)$ and female $(49 \%)$ was included in the sample. About $62.3 \%$ of the study cohort subject's age was between 23-25 years and half of them have normal weight (46.6\%). The majority were single and $34 \%$ were in the fifth-year medical school.

Table 1: -The socio-demographic characteristics of the studied subjects

\begin{tabular}{|l|c|}
\hline Characteristics & No. (\%) \\
\hline Age in years & $91(36.8 \%)$ \\
$19-22$ & $154(62.3 \%)^{\#}$ \\
$23-25$ & $2(0.8 \%)$ \\
more than 25 & \\
\hline Sex & \\
\hline
\end{tabular}




\begin{tabular}{|l|c|}
\hline Male & $126(51 \%)$ \\
Female & $121(49 \%)$ \\
\hline Marital status & $225(91.1 \%)$ \\
Single & $20(8.1 \%)$ \\
Married & $2(0.8 \%)$ \\
Divorced & \\
\hline Medical year & $22(8.9 \%)$ \\
First year & $29(11.7 \%)$ \\
Second year & $47(19 \%)$ \\
Third year & $41(16.6 \%)$ \\
Fourth year & $84(34 \%)^{\#}$ \\
Fifth year & $24(9.7 \%)$ \\
Intern & \\
\hline Grade Point Average (GPA) & $63(25.5 \%)$ \\
$4.5-5.00$ & $118(47.8 \%)$ \\
3.75 - 4.49 & $61(24.7 \%)$ \\
$2.75-3.74$ & $5(2 \%)$ \\
Less than 2.74 & $42(17 \%)$ \\
\hline Smokering (including shisha and others) & $205(83 \%)^{\#}$ \\
Yes & $37(15 \%)$ \\
No & $115(46.6 \%)^{\#}$ \\
\hline Body mass index (BMI) & $68(27.5 \%)$ \\
18.4 or less & $27(10.9 \%)$ \\
18.5 - 24.9 & \\
25.0 - 29.9 & $2(0.8)$ \\
30 or more & $6(2.4)$ \\
\hline Associated conditions & $5(2)$ \\
Diabetes & $35(14.2)$ \\
Hypertension & $6(2.4)$ \\
Thyroid disease & $48(19.4)$ \\
Anemia & $48(19.4)$ \\
Scalp infection & $24(9.7)$ \\
Acne & $128(51.8)$ \\
Vitamin deficiencies & $5(2)$ \\
Psychiatric diseases (depression , anxiety ... etc ) & \\
None & \\
others & \\
\#The most common & \\
\hline
\end{tabular}

By asking the students if they have hair loss (alopecia) or Irritable bowel syndrome (IBS), 114 students (46.1\%) said they have hair loss (alopecia), 92 students (37.2\%) have IBS. both diseases were presented with extreme statistical significance. Most of students $(194,78.5 \%)$ reported no intake of specific medications which can affect hair loss or IBS (like anticoagulants, chemotherapy, antidepressants, steroids, Vitamin A, or oral contraceptive pill for females).

Table 2, shows the characteristics of students with hair loss (alopecia). There was a statistical significance in students with alopecia suffering from hair loss in places elsewhere in the body ( $\mathrm{p}$ value $<0.0001$ ). Also, there were significant duration of hair loss (> 3 months), most of the students $(82 / 114,71.9 \%)$ are not using chemicals or coloring for their hair. Most of students suffering from hair loss (110/114, 96.5\%) use shampoo, 42 students (36.8\%) use blowing hair dryer, 12 students (11\%) uses natural henna, and 10 students (8.7\%) use hair gel.

Table 2: -Characteristics of subjects with Hair loss.

\begin{tabular}{|l|c|c|}
\hline Characteristics & No. of subjects (total, \%) & P value \\
\hline Hair loss (alopecia) & $114(247,46.1 \%)^{*}$ & $<0.0001 *$ \\
\hline Hair loss elsewhere on the body & $14(114,12.3 \%)$ & $<0.0001^{*}$ \\
\hline $\begin{array}{l}\text { Duration of hair loss } \\
\text { Less than 3 months }\end{array}$ & $4 \quad(114,3.5)$ & $<0.0009 *$ \\
\hline
\end{tabular}




\begin{tabular}{|l|c|c|}
\hline More than 3 months & $110(114,96.5)$ & $<0.0005^{*}$ \\
\hline +ve compulsion to pull-out hair & $26(114,22.8)$ & $<0.0001 *$ \\
\hline $\begin{array}{l}\text { Hair loss affect or interfere with student's } \\
\text { life in general }\end{array}$ & $97(114,85)$ & $<0.0019^{*}$ \\
\hline Hair loss affect the academic performance & $17(114,15)$ & $<0.0053 *$ \\
\hline $\begin{array}{l}\text { Students sought medical advice for hair } \\
\text { loss }\end{array}$ & $34(114,29.8)$ & 0.8947 \\
\hline Family history of hair loss & $56(114,49)$ & \\
\hline
\end{tabular}

* Using Fisher's exact test

Table 3, shows characteristics of students with Irritable Bowel Syndrome (IBS). The cohort subjects who suffered from abdominal pain \& discomfort $(72,74.2 \%)$, diarrhea $(49,50.5 \%)$, constipation $(50,51.5 \%)$, bloating of stomach $(69,71.1 \%)$, urgent need to go to the toilet $(42,43.3 \%)$, mucus in the stool (white, stringy or foamy bubbles) $(31,32$ $\%)$, and only 10 students $(10.3 \%)$ reported no symptoms despite they were diagnosed to have IBS.

Table 3: - Characteristics of subjects with Irritable Bowel Syndrome (IBS)

\begin{tabular}{|l|c|c|}
\hline Characteristics & No. of subjects (total, \%) & P value \\
\hline Irritable bowel syndrome (IBS) & $92(247,37.2 \%)^{* *}$ & $<0.0001^{* *}$ \\
\hline $\begin{array}{l}\text { IBS diagnosed by a doctor or by licensed } \\
\text { physician }\end{array}$ & $25(92,27.1)$ & \\
\hline $\begin{array}{l}\text { Duration of IBS symptoms } \\
\text { Less than 6 months } \\
\text { More than 6 months }\end{array}$ & $17(92,18.4)$ & $<0.00053^{* * *}$ \\
\hline The pain relived by defecation & $75(92,81.6)$ & $<0.0001^{* *}$ \\
\hline $\begin{array}{l}\text { IBS affect or interfere with the student's } \\
\text { life in general }\end{array}$ & $75(92,81.6)$ & $<0.0006^{* *}$ \\
\hline $\begin{array}{l}\text { Effect of IBS on the academic } \\
\text { performance }\end{array}$ & $83(92,90.2)$ & 0.461 \\
\hline Sought medical advice for IBS & $49(92,53.2)$ & $0.027^{*}$ \\
\hline Started any special diets recently & $38(92,41.3)$ & $<0.0001^{* *}$ \\
\hline
\end{tabular}

**Using Chi-square test

* Using Fisher's exact test

When investigating stress among the study population as an important cause of alopecia and IBS, we found that almost all the students feel stressed, and 35.2\% feel stress specifically during exams periods. The majority of them $(94 \%)$ thought that studying in the college of medicine and having too much work are the main causes of this stress. About 169 subject (68.4\%) feels nervous when stressed, while 107 (43.3\%) and 95 (38.5\%) feels not well and tired during stress, respectively. Only 65 subject (26.3\%) experience difficulty in sleeping during stress. The response of the cohort students to stress was surprising, 100 students $(40.5 \%)$ said they did nothing, 102 students (41.3\%) respond by crying and shouting, 77 students (31.2\%) respond by eating. Only 40 students (16.2\%) and 35 students $(14.2 \%)$ do sports and recreation activities during stress, respectively.

Table 4, shows the characteristics of stress among the study population. When asking the students for the expected complications of stress, they answered: Depression \& Anxiety (173, 70\%), Heart Disease (100, 40.5\%), Hypertension (49, 121\%), Susceptibility to Infections (54, 21.9\%), Irritable bowel syndrome (147, 59.5\%), Peptic Ulcers $(111,44.9 \%)$, Weight Gain $(122,49.4 \%)$, Exacerbation of existing diabetes (51, 20.6\%), Muscular and Joint Pain (42, 17\%), Headaches (150, 60.7\%), Sleep disturbances (179, 72.5), Sexual \& reproductive dysfunction $(60$, $24.3 \%$ ), Affection on memory, concentration and learning (127, 51.4\%), Unexplained hair loss (103, 41.7\%), Exacerbation of existing skin disease (35, 14.2\%), Substance abuse (69, 27.9).

Table 4:- Characteristics of Stress among the study population.

\begin{tabular}{|l|c|c|}
\hline Characteristics & No. of subjects (total, \%) & P value \\
\hline $\begin{array}{l}\text { Stress affect student's educational } \\
\text { attainment }\end{array}$ & $141(247,57.1)$ & $0.0022^{* *}$ \\
\hline Student's membership in any social clubs & $147(247,59.5)$ & $<0.0001 * *$ \\
\hline Stress during working in social club & $64(147,43.8)$ & $0.0358^{* *}$ \\
\hline
\end{tabular}

**Using Chi-square test 
The majority of the studied subjects showed no statistically significant differences between male and female subjects in almost all aspects of the study. When asking the females specifically, they show statistically extreme significant differences regarding having regular menstrual cycles $(86 / 121,71 \%)$; $\mathrm{p}$ value $<0.0001$ and regarding having excess hair on chin, face, abdomen $(31 / 121,25.6 \%)$; p value $<0.0057$. But, there were no significant difference when investigating being pregnant before $(5 / 121,4.1)$; p value $=0.032$.

\section{Discussion: - \\ IBS: -}

Several studies have shown different prevalence rates of irritable bowel syndrome among different populations. A meta-analysis was carried out in 2012 on the epidemiology of irritable bowel syndrome and calculated roughly a global prevalence of $11.2 \%$ [15]. In Western countries, it was estimated that the prevalence of IBS varied in the range of $15 \%-24 \%$ [16]. In addition, it has been reported in Asia that the prevalence was approximately 10-20\% [17]. The results of this study show a higher prevalence of IBS 37.2\% among medical students and interns in Madina, Saudi Arabia. The disparity between the current study and the previous studies proposesthat there might be a true difference between countries. It may be of interest in the future to endeavor to correlate these differences with the cultural and dietary habits in various countries [18]. Further reasons may be assigned to sample size, ethnic variations, age group, and diagnostic criteria used.

Comparing IBS prevalence among different types of students, a study conducted in China has been able to demonstrate that medical students had a higher risk of any FBD than science and engineering students. [19] Furthermore, Costanian et al. reported an overall prevalence of IBS among university students in Beirut, Lebanon which was $20 \%$, and over $50 \%$ of those students who reported having IBS were medical students [20]. A possible explanation for this might be that medical education is considered to be among the most arduous and the most laborious education [14]. Due to their exceptional lifestyle (numerous exams and overwrought clinical practice in hospital) together with enormous stress and inadequate capability of adaptation and conformity, medical students may be an especially high-risk population for IBS [13]. A local research was conducted among medical students in Jeddah, Saudi Arabia which is in agreement with the current study reported that the rate of IBS was 31.8\% [14]. High prevalence rate of IBS among medical students was also recorded in Japan which was 35.5\%. [21] Similar researches with approximately similar prevalence rates were done in different countries such as Korea (29.2\%) [22], China (33.3\%) [13], Karachi, Pakistan (28.3\%) [23] and another study was also inKarachi and Bahawalpur, Pakistan $(34 \%)$ [24] are all in line with the results of the current study.

Females are more likely to suffer from IBS in Western countries, as many studies established [25]. This finding is in concordance with this research which reports modestly higher prevalence of IBS among females compared to males (22.2\% vs $17 \%$ of total 247 ) and seems to be consistent also with data obtained from various studies around the world [16,19,23,26,27,28,29]. Nevertheless, the main cause of gender variation in IBS prevalence is still undetermined and open to question. This finding can be explained in part by the differences in social and cultural aspects such as health care seeking behavior between males and females or it may be due to actual physiological differences such as menstrual cycle alterations which by unknown mechanism exacerbate bowel symptoms during menses [25].

This research also demonstrates that $41.3 \%$ of students who have IBS have sought medical attention and diagnosed by a licensed doctor. Accordingly, Ghanaei et al. [30] illustrated in a similar study that $37.7 \%$ of student had visited physicians. These results are in accord with recent studies in Bangladesh [31] and Jeddah [14].

IBS effect on patients' lives can be considerably important. its symptoms may disarrange their daily routine forcing them to miss school, reduce social activities and interactions, skip meals or make other changes to diet and nutrition [32]. The current study reveals that $53.2 \%$ of students who have IBS affects their educational attainment and their academic performance. While $90.2 \%$ of students who have IBS believe that it affects or interferes with their lives in general. Also, 25.9\% of students started special diets in order to ease their suffering. Studies have reported that IBS is a main reason for high absences and low productivity. In general, patients who have unmanaged IBS report high reductions in their overall quality-of-life [32]

\section{Hair Loss: -}

Walli H, Ghazal H, German S, Ali M and Zuberi BF said that a total of 375 female students participated in the study. The mean \pm SD age was $20.5 \pm 1.4$ years. Cross-tabulating the stress grades with hair loss showed that all of 
the hair fall victims had moderate stress. no significant difference was seen in frequencies of hair fall on the level of stress ( $\mathrm{p}=0.221$ ) [33]. Moreover, Joseph N, Kumar GS, Nelliyanil M said in their study of 278 medical students that Most of the participants $171(61.5 \%)$ were of the age group 20-21 years and majority were females 148 (53.2\%). The most common hair/skin morbidities suffered in the past one year were hair loss 165 (59.3\%) [34]. While Waka Ishida, Teruhiko Makino and Tadamichi Shimizu Said thatThe reports of hair loss in the scalp due to hair dyes containing PPD is rare, and there have been only 2 reported cases of hair loss in the scalp due to a PPD allergy associated with dermatitis in a consumer-based study (Søsted H, Agner T, Andersen KE, Menné T said that 55 cases of allergic reactions to hair dye: a descriptive, consumer complaint-based study) [35,36] . Waka Ishida, Teruhiko Makino and Tadamichi Shimizu in their case of a patient who experienced severe hair loss after the use of a hair dye containing PPD. We concluded that the explanation for the severe hair loss in our case was a concurrent sensitization and allergic reaction to PPD, as the product had been applied repeatedly over a long period of time [37]. men whose fathers had hair loss were 2.5 times as likely to have had some level of hair loss compared to men whose fathers had no hair loss (95\% CI: 1.3-4.9). Likewise, men whose fathers had hair loss were twice as likely to have hair loss than men whose fathers had no hair loss [38].

In this studywhich is a cohort of 247 medical students at Taibah university (126 males, 51\%) and 121 females, 49\%) respond to the questionnaire. The study assessed the prevalence of hair loss and Irritable Bowel Syndrome (IBS) and evaluated their effect on the student's lifestyle and educational attainment through a population-based cross-sectional study. Regarding hair loss, we found that the characteristics of students with hair loss (alopecia). There was a statistical significance in students with alopecia suffering from hair loss in places elsewhere in the body (p value < 0.0001). Also, there were significant duration of hair loss (> 3 months), most of the students $(82 / 114,71.9 \%)$ are not using chemicals or coloring for their hair. 12 students $(11 \%)$ uses natural hinna.97 $(114,85 \%)$ hair loss affects or interfere with student's life in general and $17(114,15 \%)$ hair loss affects the academic performance (stress), also 56 $(114,49 \%)$ Family history of hair loss.

\section{Stress: -}

In the present study, when investigating stress among the study population as an important cause of alopecia and IBS, we found that almost all the students feel stressed, the majority of them (94\%) thought that studying in the college of medicine and having too much work are the main causes of this stress, this finding is similar to the outcome of several study reports [1,7]. In the present study, number of subjects who said yes about the stress affecting their educational attainments $141(57.1 \%)$. This finding is in agreement with results of study [7]. In our study, number of students who participate in social clubs is 147 (59.5\%). Out of 147, 46 (43.8\%) said that working in social clubs causes stress for them.

\section{Limitations: -}

It may not be accurate answers to some of the students because the study relied on self-answers to the student. The Participants enrolled in the study may not be very representative of the whole country.

\section{Conclusion: -}

The results of this study show a higher prevalence of IBS among medical students and interns in Madina, Saudi Arabia. Many studies have shown that prevalence of IBS is the highest among medical students compared to other majors, Females are more likely to suffer from IBS.About half of students who have IBS affects their educational attainment and their academic performance. Hair loss affects or interfere with student's life in general. Hair loss affects the academic performance (stress) for few of students. All the students feel stressed, the stress affecting in the educational attainments for the majority of students.

\section{Recommendations: -}

Finally, we recommend that

1. Further studies on the same subject include larger groups of students in more specialties include larger areas in Saudi Arabia.

2. Perform educating campaigns to educate the students about the complications of stress and how to avoid it.

3. Statement of the university's role in reducing stress and its complications among students, and stimulate the universities to play this role. 


\section{Acknowledgment: -}

In performing our research, we had to take the help and guideline of some respect person, who deserve our greatest gratitude. The completion of this research give us much pleasure. We would like to show our gratitude for Dr.Hany Hadedfor giving us a good guideline for research throughout numerous consultations. And we are thankful for our college for give us a suitable environment and facilitate the paperwork to complete our research, and our colleagues in Taibah university who give us their time to complete the questionnaire.

\section{References:-}

1. Eva, E. O., Islam, M. Z., Mosaddek, A. S. M., Rahman, M. F., Rozario, R. J., Iftekhar, A. F. M. H., ... Haque, M. (2015). Prevalence of stress among medical students: a comparative study between public and private medical schools in Bangladesh. BMC Research Notes, 8, 327. http://doi.org/10.1186/s13104-015-1295-5

2. Bercik P, Verdu EF, Collins SM. Is irritable bowel syndrome a low-grade inflammatory bowel disease?. $\begin{array}{lllll}\text { GastroenterolClin North } & \text { Am. } & 2005 & \text { Jun. } & \text { 34(2):235-45, }\end{array}$ vivii.http://reference.medscape.com/medline/abstract/15862932

3. 3- Spiegel BM, Farid M, Esrailian E, Talley J, Chang L. Is irritable bowel syndrome a diagnosis of exclusion?: a survey of primary care providers, gastroenterologists, and IBS experts. Am J Gastroenterol. 2010 Apr. 105(4):848-58. http://reference.medscape.com/medline/abstract/20197761

4. Canavan, C., West, J., \& Card, T. (2014). The epidemiology of irritable bowel syndrome. Clinical Epidemiology, 6, 71-80. http://doi.org/10.2147/CLEP.S40245

5. Prevalence of Stress and its Relation to Hair fall in Female Medical Students Hurmat Walli1, Hira Ghazal1 , Sidra German1 , Muneeba Ali1 , Bader FayyazZuberi. December2013 https://www.researchgate.net/profile/Bader_Zuberi/publication/258446516_Prevalence_of_Stress_and_its_Rela tion_to_Hair_Fall_in_Female_Medical_Students/links/550501070cf24cee3a02f113.pdf?origin=publication_det ail

6. Abdulghani, H. M., AlKanhal, A. A., Mahmoud, E. S., Ponnamperuma, G. G., \&Alfaris, E. A. (2011). Stress and Its Effects on Medical Students: A Cross-sectional Study at a College of Medicine in Saudi Arabia. Journal of Health, Population, and Nutrition, 29(5), 516-522.

7. Leta Melaku, AndualemMossie, and AlemayehuNegash, "Stress among Medical Students and Its Association with Substance Use and Academic Performance," Journal of Biomedical Education, vol. 2015, Article ID 149509, 9 pages, 2015. doi:10.1155/2015/149509

8. Dahlin M, Joneborg N, Runeson B. Stress and depression among medical students: a cross-sectional study. Med Educ. 2005;39(6):594-604.

9. Joseph, N., Kumar, G. S., \&Nelliyanil, M. (2014). Skin diseases and conditions among students of a medical college in southern India. Indian Dermatology Online Journal, 5(1), 19-24. http://doi.org/10.4103/22295178.126023

10. Chang, L. (2011). The Role of Stress on Physiological Responses and Clinical Symptoms in Irritable Bowel Syndrome. Gastroenterology, 140(3), 761-765. http://doi.org/10.1053/j.gastro.2011.01.032

11. Nora I. Osemene (2015) Irritable Bowel Syndrome in Children and Adolescents. US Pharmacist. 2015;40(5):46-50. http://www.medscape.com/viewarticle/845872 5

12. Naeem, S. S., Siddiqui, E. U., Kazi, A. N., Memon, A. A., Khan, S. T., \& Ahmed, B. (2012). Prevalence and factors associated with irritable bowel syndrome among medical students of Karachi, Pakistan: A crosssectional study. BMC Research Notes, 5, 255. http://doi.org/10.1186/1756-0500-5-255

13. Liu, Y., Liu, L., Yang, Y., He, Y., Zhang, Y., Wang, M., ... Yao, S. (2014). A School-Based Study of Irritable Bowel Syndrome in Medical Students in Beijing, China: Prevalence and Some Related Factors. Gastroenterology Research and Practice, 2014, 124261. http://doi.org/10.1155/2014/124261

14. Ibrahim, N. K. R., Battarjee, W. F., \&Almehmadi, S. A. (2013). Prevalence and predictors of irritable bowel syndrome among medical students and interns in King Abdulaziz University, Jeddah. The Libyan Journal of Medicine, 8, 10.3402/ljm.v8i0.21287. http://doi.org/10.3402/ljm.v8i0.21287

15. Lovell RM, Ford AC. Global prevalence of and risk factors for irritable bowel syndrome: a metaanalysis. ClinGastroenterol Hepatol. 2012;10:712-721.http://www.ncbi.nlm.nih.gov/pubmed/22426087

16. Dong YY, Zuo XL, Li CQ, Yu YB, Zhao QJ, Li YQ. Prevalence of irritable bowel syndrome in Chinese college and university students assessed using Rome III criteria. World J Gastroenterol. 2010; 16: 42216. 
17. Kanazawa M, Endo Y, Whitehead WE, et al. Patients and non-consulters with irritable bowel syndrome reporting a parental history of bowel problems have more impaired psychosocial distress. Dig Dis Sci.2004;49:1046-1053.http://www.ncbi.nlm.nih.gov/pubmed/15309899

18. Hungin AP, Whorwell PJ, Tack J, Mearin F. The prevalence, patterns and impact of irritable bowel syndrome: an international survey of 40,000 subjects. Aliment PharmacolTher. 2003; 17: 64350.

19. Chu L, Zhou H, Lu* B, Li M, Chen MY. [An epidemiological study of functional bowel disorders in Zhejiang college students and its relationship with psychological factors]. ZhonghuaNeiKeZaZhi. 2012; $51: 42932$.

20. Costanian, Christy, Hala Tamim, and ShafikaAssaad. "Prevalence and Factors Associated with Irritable Bowel Syndrome among University Students in Lebanon: Findings from a Cross-Sectional Study." World Journal of Gastroenterology: WJG 21.12 [2015]: 3628-3635. PMC. Web. 5 July 2016.

21. Okami Y, Kato T, Nin G, Harada K, Aoi W, Wada S, et al. Lifestyle and psychological factors related to irritable bowel syndrome in nursing and medical school students. J Gastroenterol. 2011; 46: 140310.

22. Jung HJ, Park MI, Moon W, Park SJ, Kim HH, Noh EJ, et al. Are food constituents relevant to the irritable bowel syndrome in young adults? A Rome III based prevalence study of the Korean medical students. J NeurogastroenterolMotil. 2011; 17: 2949.

23. Naeem SS, Siddiqui EU, Kazi AN, Memon AA, Khan ST, Ahmed B. Prevalence and factors associated with irritable bowel syndrome among medical students of Karachi, Pakistan: a cross-sectional study. BMC Res Notes. 2012; 5: 255.

24. Jafri W, Yakoob J, Jafri N, Islam M, Ali QM. Frequency of irritable bowel syndrome in college students. J Ayub Med Coll Abbottabad. 2005; 17: 911.

25. Lee OY, Mayer EA, Schmulson M, Chang L, Naliboff B. Gender-related differences in IBS symptoms.Am J Gastroenterol. 2001;96:2184-93. doi: 10.1111/j.1572-0241.2001.03961.x.

26. Adeyemo MA, Chang L. New treatments for irritable bowel syndrome in women. Womens Health. (LondEngl) 2008; 4: 60522; quiz 623.

27. Song SW, Park SJ, Kim SH, Kang SG. Relationship between irritable bowel syndrome, worry and stress in adolescent girls. J Korean Med Sci. 2012; 27: 1398404.

28. Okami Y, Kato T, Nin G, Harada K, Aoi W, Wada S, et al. Lifestyle and psychological factors related to irritable bowel syndrome in nursing and medical school students. J Gastroenterol. 2011; 46: 140310.

29. Jahangiri P, Jazi MS, Keshteli AH, Sadeghpour S, Amini E, Adibi P. Irritable Bowel Syndrome in Iran: SEPAHAN systematic review No. 1. Int J Prev Med. 2012; 3(Suppl 1): S19.

30. Mansour-Ghanaei F, Fallah MS, Heidarzadeh A, Jafarshad R, Joukar F, Rezvan-Ghasemipour, et al. Prevalence and characteristics of irritable bowel syndrome (IBS) amongst medical students of Gilan Northern Province of Iran. MEJDD. 2011; 1: 1005.

31. Masud MA, Hasan M, Khan AK. Irritable bowel syndrome in a rural community in Bangladesh: prevalence, symptoms pattern, and health care seeking behavior. Am J Gastroenterol. 2001; 96: 154752.

32. The, T., Test, I. B. S., Irritable, U., Syndrome, B., \& Brochure, A. C. E. (n.d.). YES NO UNDERSTANDING IRRITABLE BOWEL SYNDROME Abdominal Discomfort or Pain of Americans suffer from abdominal pain , bloating , and diarrhea . Now new treatments can relieve your pain, 16.http://www.iwk.nshealth.ca/sites/default/files/IBS_handout.pdf

33. Walli H, Ghazal H, German S, Ali M, Zuberi BF. Prevalence of stress and its relation to hair fall in female medical students. J Pioneer Med Sci 2013; 3(4):205-207

34. Joseph N, Kumar GS, Nelliyanil M. Skin diseases and conditions among students of a medical college in southern India. Indian Dermatol Online J 2014;5:19-24

35. Waka Ishida, Teruhiko Makino, Tadamichi Shimizu Severe Hair Loss of the Scalp due to a Hair Dye Containing Para phenylenediamine SRN Dermatol. 2011; 2011: 947284.

36. Søsted H, Agner T, Andersen KE, MennéTContact Dermatitis. 2002 Nov; 47(5):299-303.

37. Waka Ishida, Teruhiko Makino, Tadamichi Shimizu. Severe Hair Loss of the Scalp due to a Hair Dye Containing Para phenylenediamine. 2011; 2011: 947284.

38. Chumlea WC, Rhodes T, Girman CJ, Johnson-Levonas A, Lilly FR, Wu R, Guo SS. Family history and risk of hair loss. 2004;209(1):33-9. 